\title{
The Impact of Perceived Advertising Creativity on Behavioural Intentions and Quality Perceptions in Mass Customization
}

\author{
Thomas Aichner \\ Assistant Professor of Marketing, College of Business, Alfaisal University, \\ P.O. Box 50927, Riyadh 11533, Kingdom of Saudi Arabia, mail@thomasaichner.eu \\ Abdel Monim Shaltoni \\ Associate Professor of Marketing, College of Business, Alfaisal University, \\ P.O. Box 50927, Riyadh 11533, Kingdom of Saudi Arabia, ashaltoni@alfaisal.edu
}

Received (5.11.2018.); Revised (3.03.2019); Accepted (6.03.2019.)

\begin{abstract}
This is the first article to study the influence of perceived advertising creativity on behavioural intentions and perceived product quality in mass customization. Through an online survey, 300 Saudi participants evaluated one of three fictitious miadidas sneakers advertisements, which were manipulated through the use of different product configurations. These product configurations had different levels of perceived creativity, which consequently influenced the perceived advertising creativity of the overall advertisement. The results show that perceived advertising creativity is an excellent predictor for behavioural intentions such as the customer's willingness to visit the advertiser's website and to try out customizing the product using a web-based sales-configurator. The more creative the advertisement is perceived by the customer, the higher is his or her behavioural intention. In contrast, the correlation between perceived advertising creativity and perceived product quality is weak and negative.
\end{abstract}

Key words: Advertising, Consumer Perception, Creativity, Mass Customization, Young Consumers

\section{INTRODUCTION}

It is increasingly hard to predict and/or generalise the behaviour of consumers. Many of today's consumers are influenced by globalisation, popular cultures, countless micro trends, many macro trends, and the socalled megatrends, e.g. social and demographic change or technological breakthroughs. Since just a few decades, mainly Western societies have been heavily aging, while others have an overwhelmingly young population. For example, almost $70 \%$ of Germans are 30 years or older, while more than $60 \%$ of the people living in the Kingdom of Saudi Arabia are younger than 30 years of age. These young adults have diverse needs, wants, perceptions, and behave differently. This is, for example, because they are more savvy when it comes to digital and mobile technologies. Commonly referred to as "digital natives", this young generation spends more time online, is more inclined to buy products on the Internet, and is generally more likely to adopt technologies such as the use of online or mobile configurators to customize a product according to their individual needs and preferences before ordering it, i.e. to engage in mass customization.

The underlying idea of mass customization (MC) is to produce customized products to satisfy individual customer needs at a similar price of mass-produced products [1]. With the help of smart factories, cyber- physical systems and the internet of things, generally referred to as Industry 4.0 [2], companies, even small ones [3], are now able to successfully combine the two conventional manufacturing strategies that were traditionally considered to be mutually exclusive: mass production on one hand and craft manufacturing on the other hand. After more than 30 years of research, the goal of producing customized products with mass production efficiency is now closer within reach than ever before.

There is a significant amount of research assessing the technical, operational, and management aspects of MC. However, although there is some research about consumer behaviour, consumer motivation, and consumer preferences in MC [e.g. 4], little is known about how companies should advertise their MC products. As advertising creativity increases the perceived value of the advertised product [5], the focus of this work is to find out whether advertising creativity, which is manipulated by using more or less creative MC product configurations in advertisements, impacts on (a) customer's behavioural intention, e.g. the customer's willingness to visit the advertiser's website, and (b) perceived product quality. 


\section{REVIEW OF THE LITERATURE AND HYPOTHESES}

Researchers confirm that $M C$ is a noteworthy research area $[6,7]$, as it is one of the most important competitive strategies [8] and one of the most relevant production trends in developed countries [9], which is also becoming more diffused in developing countries [10].

One trend in $M C$ is to offer interactive, web-based sales-configurators that allow customizing the product $[7,11,12]$. Typically, such a configurator guides the user in generating or searching for product configurations, supplies information in real time on the customization feasibility, price and other technical details, and generates a sales offer [13], which then may be accepted by the final consumer.

From a consumer perspective, the value of MC products is determined by intrinsic (hedonic, price) and extrinsic (utilitarian, individualism/uniqueness, self-expression) drivers $[11,14,15]$. Customers derive benefits from the possession of the customized product and from the experience of customizing the product itself [15]. What makes the experience during the customization process from need awareness to finalization [16] valuable to the customer is twofold: First, the gamification of the process [15], which results in benefits that derive from the pure experience of customizing a product even if the process is not completed [17] because it allows customers to "come up with new and creative combinations" [18, p. 127], and second, the pride of authorship [14] that leads to creative-achievement benefits when the customization is completed and the customer felt that he or she had control over the process [17]. The benefits that are obtained from the possession of customized products can also be grouped in different categories: utilitarian benefits, such as better fit and increased comfort, the facilitation of self-expression, and the assertion of personal distinctiveness and uniqueness [15, 19, 20, 21]. Individualism, uniqueness, self-expression, and distinctiveness are concepts related to creativity, which literally means "create", "invent", and "discover" [22] and generally refers to the development of novel and useful ideas or products $[23,24,25]$. MC research has been focussing on the actual customization stage, but not so much on the pre-customization stage, i.e. the advertising of MC products and online salesconfigurators. Advertising creativity is an unexplored area in MC literature.

\subsection{Advertising Creativity}

Research revealed that advertising creativity impacts on cognitive, affective, and conative variables [26]. Advertising creativity has, for example, a positive effect on the recall and recognition of slogans in an incidental learning context [27]. Smith et al. [26] found that advertising creativity has an effect on each hierarchy-ofeffects stage, which acts as a mediator, and also exerts a direct (unmediated) effect on brand awareness and brand liking. In a more practically oriented study, Reinartz and Saffert [28] demonstrated a "dramatic variation" in creativity scores with an average score of 2.98 (on a scale of 1 to 7 ), with only 11 out of 437 campaigns receiving an overall score above 5 . They further found that these scores had a significant influence on the success of advertising, as a dollar invested in a highly creative ad campaign almost doubled the sales impact as compared to a noncreative campaign.

Although researchers largely agree on the value of creativity and see it as an essential component of advertising [29], it may not always work. For example, the impact of creativity on sales differs by product category [28]. Reinartz and Saffert [28] showed that especially for functional products that are oriented toward clear consumer goals (e.g. detergents), novel approaches are less preferable.

Dahlén et al. [30, p. 329] summarize the role of creativity in advertising with "advertising creativity matters", while Belch and Belch [31, p. 395] underline that "creativity, which has been shown to impact the success of a product [...] will continue to remain an important factor in marketing communications into the future".

\subsection{Hypotheses Development}

There are many reasons why consumers engage in MC and design their own product. Several studies show that $M C$ creates value through the exciting experience of the customization on the one hand, and by offering consumers the possibility to develop creative [32], differentiated, and unique products $[33,34]$ on the other hand. Before consumers actually engage in $\mathrm{MC}$ or any other activity, they consciously and/or subconsciously [35] develop a certain degree of intention to behave or to not behave in a specific way, i.e. consumer behavioural intention, which is a function of attitude toward the behaviour [36] and defined as "the degree to which a person has formulated conscious plans to perform or not perform some specified future behavior" [37, p. 214]. Depending on the field of study, behavioural intention includes different activities that are most relevant for the underlying problem.

From a MC perspective, important objectives of advertising are to invite and convince customers to visit the website and to try out the online sales-configurator. Furthermore, the possibility to customize a product can be communicated either directly by the company through advertising or indirectly through word-of-mouth (WOM), which is defined as the act of exchanging marketing information between consumers [38]. Previous research has pointed out the importance of WOM, i.e. the consumer's willingness to recommend MC to their friends [39] or business partners [40]. For the purpose of this study, we therefore define consumer behavioural intention as the combination of willingness to visit the company's website, to try out the customization of the advertised product, and to generate WOM.

According to the theory of planned behavior [41], perception, e.g. the perception of an advertisement, influences attitudes, and attitude is an antecedent to behavioural intention. It has repeatedly been shown that high levels of advertising creativity influence attitudes and enhance consumer behavioural intentions [26, 42, $43,44,45]$. Therefore, it is hypothesised that more 
creative advertisements, e.g. by using illustrations of MC products that are perceived to be, for example, unique and novel, impact on consumer behavioural intentions.

Formally:

H1: The use of more creative advertisements when advertising mass customization products has a positive effect on consumer behavioural intention.

Another important aspect in MC is consumer's trust in the company's ability to meet promised quality levels [46]. Marketing research has pointed out the importance of perceived product quality, i.e. the consumer's judgment about a product's overall excellence [47], which-in contrast to objective or physical quality-is subjective and exists in consumers' minds [48]. Previous research has shown that perceived advertising creativity implicitly communicates and therefore positively impacts on perceived product quality [5], for example because a high level of creativity signals greater effort by the advertiser [30, 49].

It is therefore hypothesised that:

H2: The use of more creative advertisements when advertising mass customization products has a positive effect on perceived product quality.

\section{METHODOLOGY}

The data presented in this article was collected in May 2018 through an online survey. Using the network of a professional agency, consumers were invited to participate until 300 fully answered questionnaires from Saudi nationals aged 18 to 25 were recorded. Incomplete questionnaires are not included for data analysis. The respondents were randomly shown one of three fictitious advertisements for customizable sneakers and answered 17 questions, which took them about four minutes on average. They did not see or use the web-based sales-configurator. Rather, the situation was intended to simulate a situation in which a potential customer sees an advertisement before visiting the website, using the configurator and/or telling his/her friends about the offer.

As Saudi consumers, especially younger generations, can understand English questions of a medium to high complexity, e.g. because of frequent international travel and the use bilingual product packaging in the Kingdom of Saudi Arabia [50], both the stimulus and the questions were English.

In the following, details about the stimulus, the questions, and the participants are provided.

\subsection{Stimulus}

We selected sneakers as they represent a typical and widely studied MC product that is usually customizable through an online sales-configurator [51, 52]. Specifically, we used adidas' "MI I-5923" model, which could be customized on adidas' website www.adidas.com/us/customize ${ }^{1}$ for a price of $\$ 150$. Three versions of a fictitious advertisement for customizable sneakers from miadidas, adidas' custom shoes and apparel division, were created by a professional creative from a leading advertising agency. The advertisements included the miadidas logo, the adidas logo, a visualization of the online product configurator showing both some configuration options and the sneaker, the price $(\$ 150.00)$, and a call for action (DESIGNYOUROWN > adidas.com), which greatly corresponds to real miadidas ads.

The three versions of the advertisement were manipulated by changing the product configuration only, using three designs with low, medium, and high levels of creativity (see Figure 1, Figure 2, and Figure 3).

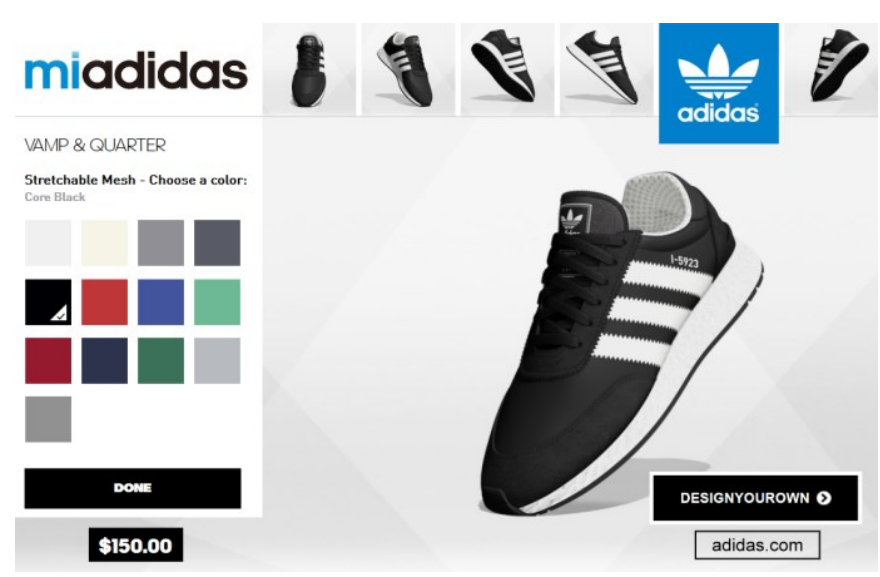

Figure 1. Fictitious advertisement for customizable sneakers from miadidas with a low creativity model

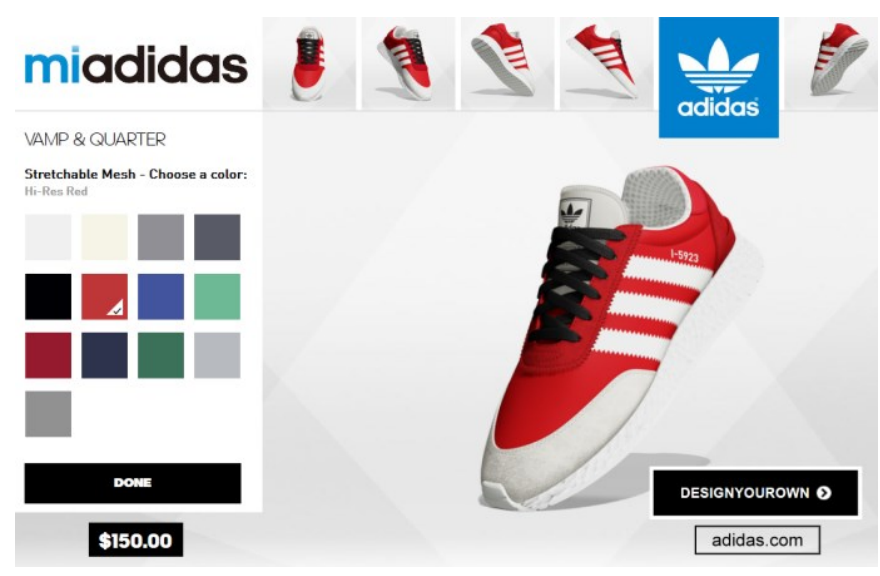

Figure 2. Fictitious advertisement for customizable sneakers from miadidas with a medium creativity model

\footnotetext{
1 According to adidas, its customization unit miadidas was discontinued on 13 January 2019 to "explore new customization options." Given that midadas, which operated from 2000 to 2019 , was considered one of the major MC platforms and cited in more than 200 MC publications according to Google Scholar, the findings of this paper should be valuable for both research and practice despite the fact the platform is offline since early 2019 .
} 


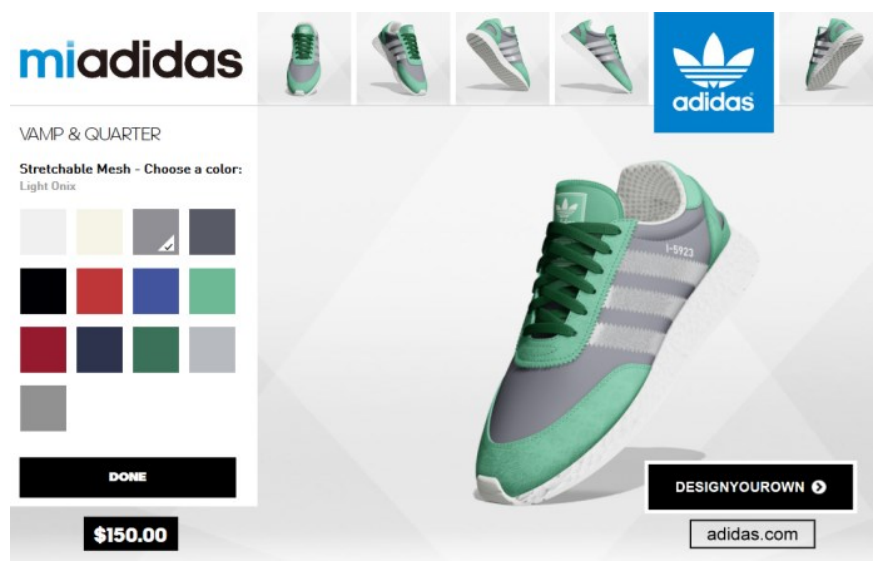

Figure 3. Fictitious advertisement for customizable sneakers from miadidas with a high creativity model

Perceptions of consumers are subjective and can vary a lot [53], i.e. one respondent may perceive a product configuration to be highly creative, while the same version may be perceived to be significantly less creative by another. This means that the present research could also have been carried out by using just one sneaker version rather than three. Although the actual level of perceived creativity in itself is not relevant for this study, it was important to make sure that all levels of perceived creativity are covered equally. Therefore, a pre-test amongst Saudi students was carried out to identify three product configurations with a low, medium, and high level of perceived creativity. To this end, 20 students from the author's institution were selected through systematic sampling and asked to evaluate the level of creativity of nine different sneaker models using the same five items described in section 3.2. The model with the lowest, an average, and highest level of creativity were selected. Using three paired sample t-tests, the levels of perceived creativity of the three models were all found to be significantly different from each other (sneaker ${ }_{\text {low }}=3.44$ vs. sneaker $r_{\text {medium }}=4.13 ; t(19)=3.851$, $p<.01$ and sneaker medium $=4.13$ vs. sneaker $_{\text {high }}=4.60$; $\mathrm{t}(19)=2.312, p<.05)$.

\subsection{Measures}

The online questionnaire included 17 questions. The three demographic questions were placed at the beginning, as they included two screening questions (age and nationality). In addition, respondents indicated their gender. The fourth question was related to product involvement. Next, the respondents saw the stimulus, which was randomly selected from the three versions of the fictitious advertisement. The stimulus was followed by five questions to measure perceived creativity, three questions regarding behavioural intentions, and five questions about perceived product quality.

As product involvement is an important dimension in consumer behaviour, e.g. as it acts as a motivator for WOM [54] it was included as a measure in this study. In line with Donthu et al. [55], who used a 4-point singleitem scale and argued the use of single-items scales can be advantageous despite the many complex constructs established in literature, product involvement was measured using a 7-point single-item scale. Respondents were asked "How relevant or important are sneakers to you?" and could choose a value between 1 (not at all relevant or important) to 7 (extremely relevant or important). However, the Pearson correlation coefficients show that product involvement $(\mathrm{M}=3.97, \mathrm{SD}=2.00)$ is not significantly correlated to any other construct under study, i.e. perceived creativity $(\mathrm{M}=3.76, \mathrm{SD}=1.53 ; \mathrm{r}(299), p=.931)$, behavioural intention $(M=3.82, \quad S D=1.56 ; \quad r(299)$, $p=.671)$, and perceived quality $(M=4.88, \quad S D=1.11$; $\mathrm{r}(299), p=.563)$. Notwithstanding product involvement is not correlated with the dependent variables, we included it in our regression models. However, its regression coefficients were not significant at $p<.10$. Therefore, to keep the model parsimonious we excluded it from the regression analysis and consequently we do not report further information on it hereafter.

To assess perceived advertising creativity, five items measuring the novelty dimension from O'Quin and Besemer's [56] Creative Product Semantic Scale were used. In line with the approach of White and Smith [57], who assessed advertising creativity of several ads, respondents saw one of the three ads and indicated on a 7-point semantic differential scale whether the advertisement is overused-fresh, predictable-novel, usual-unusual, ordinary-unique, and conventionaloriginal. The internal consistency of the construct is excellent (Cronbach's alpha=.916).

Consumer behavioural intention measures the selfreported likelihood that a person will engage in a specific action [58]. In this study, consumer behavioural intention was measured using three items, namely intention to visit the website (I will definitely visit the website), intention to try customizing the product (I will definitely try customizing the sneakers), and intention to tell others about the possibility to customize sneakers on adidas.com (I will definitely tell my friends about the possibility to customize sneakers on adidas.com). Seven-point Likert-type scales were employed (strongly disagree to strongly agree). The internal consistency of the construct is good (Cronbach's alpha=.855).

Finally, five items taken from Dodds et al. [59] were employed to assess perceived product quality. As in the original paper, the indicators and 7-point rating scales were as follows: The likelihood that the product would be reliable is: (very low to very high), The workmanship of the product would be: (very low to very high), This product should be of: (very poor quality to very good quality), The likelihood that this product is dependable is: (very low to very high), This product would seem durable (strongly disagree to strongly agree). The internal consistency of the construct is acceptable (Cronbach's alpha=.763).

All items within each set of questions for the three constructs perceived creativity, behavioural intentions, and perceived product quality were presented in random order through computer-generated random ordering. The order of each scale was randomly either positive-negative or negative-positive. For data 
analysis, all scales were adjusted and are presented from negative (1) to positive (7).

\subsection{Control of Common Method Bias}

Random and systematic measurement errors can threaten the validity about relationships between variables [60]. Therefore, we control for common method bias and common methods variance [61] by performing two factor analyses: One for perceived creativity with behavioural intention, and one for perceived creativity with perceived quality. By using Harman's single factor test, limited method bias was found, as the first factor $(40.9 \%$ and $34.9 \%$, respectively) did not explain the majority of the variance.

\subsection{Participants}

All participants $(\mathrm{N}=300)$ were mobile phone users and answered all questions on their own device. Both age (18-25 years, $M=21.62, \quad S D=2.23$ ) and nationality (Kingdom of Saudi Arabia) were exclusion criteria, as the objective of this study was to assess young Saudi consumer's perceptions and behavioural intentions. Overall, $48.3 \%$ of participants were male. The gender of the sample is also balanced regarding the three designs with low (48\% male), medium (48\% male), and high (49\% male) levels of creativity.

\section{RESULTS}

To assess $H 1$, a simple linear regression was calculated to predict behavioural intention $(M=3.82$, $S D=1.56)$ based on perceived creativity $(M=3.76$, $S D=1.53)$. A significant regression equation was found $(F(1,298)=677.152, p<.001)$, with a $R^{2}$ of .694 . The regression equation is: consumer behavioural intention $=.624+.852$ (perceived creativity), when behavioural intention and perceived creativity are measured on a 7 point scale. Behavioural intention increased .852 for each level of perceived creativity (see also Figure 4). Thus, $\mathrm{H} 1$ is supported.

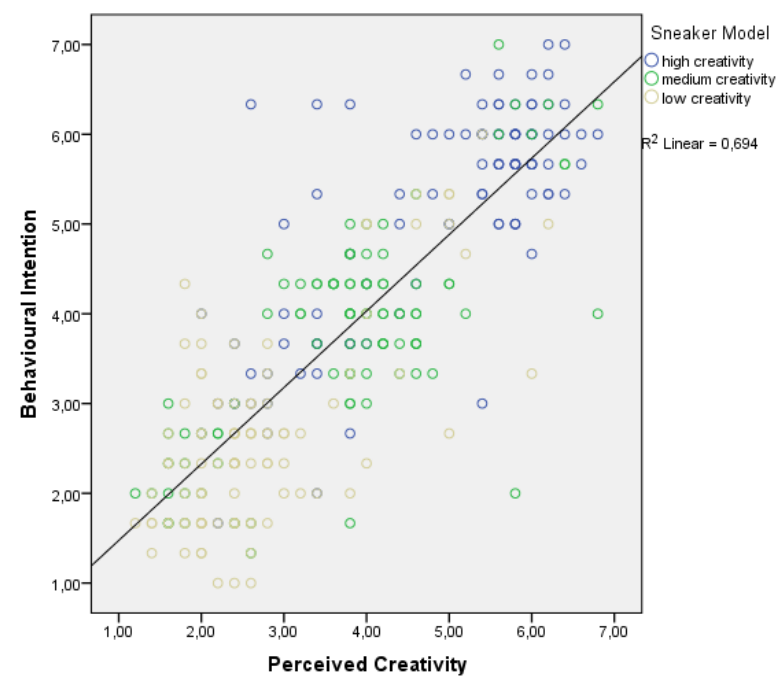

Figure 4. Scatter plot with regression line for perceived creativity and behavioural intention
$\mathrm{H} 2$ was also assessed using a simple linear regression with the goal to predict perceived quality $(M=4.88$, $S D=1.11)$ based on perceived creativity $(M=3.76$, $S D=1.53)$. With $p=.043$, the regression equation found was barely significant $(F(1,298)=4.137, p<.05)$, with $R^{2}$ of 0.014 . The regression equation is: perceived product quality $=5.196-.085$ (perceived creativity), when perceived quality and perceived creativity are measured on a 7-point scale. Perceived quality decreased .085 for each level of perceived creativity (see also Figure 5). Thus, H2 is not supported, as the hypothesised relation was positive and not negative.

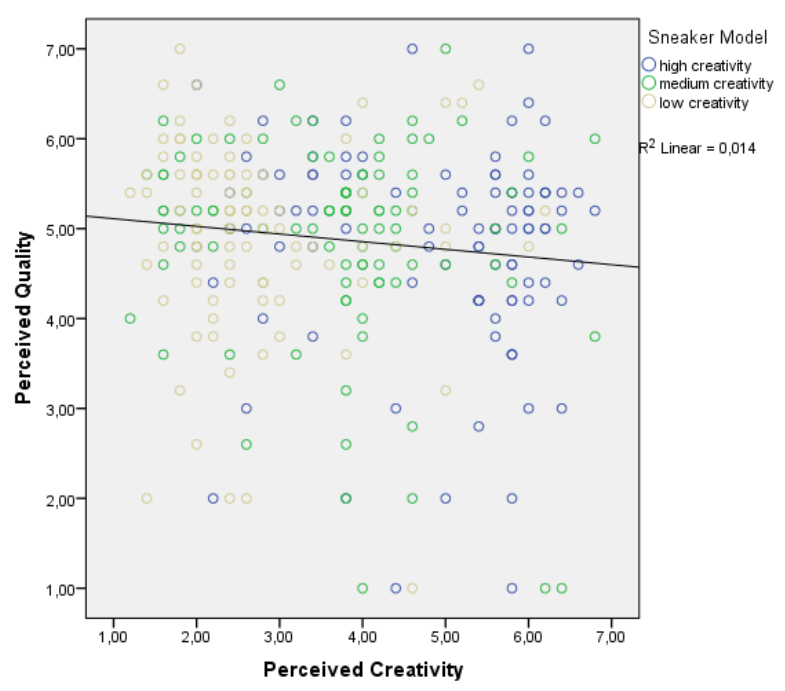

Figure 5. Scatter plot with regression line for perceived creativity and perceived quality

\section{DISCUSSION AND CONCLUSIONS}

In this study, it is shown that more creative product configurations lead to stronger behavioural intentions, i.e. consumers who perceive the advertisement to be more creative are more likely to visit the website, try out the customization process and tell their friends about the advertised product or, in other words, engage in WOM. As outlined before, advertising creativity is manipulated through the use of different product configurations, which means that companies can employ more unique and unused designs in their ads to trigger positive effects. To determine whether consumers perceive a specific product configuration to be more or less creative, it is necessary to conduct pretests. Alternatively, companies may use A/B testing with different product configurations, which is especially easy to implement in social media advertising.

When it comes to perceived product quality, the perceived level of advertising creativity does not have a large impact. In contrast to what was hypothesised, the perceived quality slightly decreases with an increase in creativity, which may have an impact on advertising decisions by companies who sell products to very quality-oriented consumers or operate in a sector where product quality is known to be a decisive factor. However, given that the results indicate that the relationship is very weak, the implications resulting from 
$\mathrm{H} 1$ may prevail and overcome the risk of a slightly lower perception of the product's quality when more creative product configurations are used in advertisements.

As a side-note, we could not find significant correlations of product involvement with any other construct used in this study, which is in contrast to most previous MC research. For example, it has been argued that customers are not willing to spend time to configure a product in low product involvement situations [62]. Similarly, it was found that higher product involvement leads to a higher probability that customers are going to customize products rather than buying a standardised version [63]. However, in a study by Schnurr and Scholl-Griessemann [64], product involvement affected customer's enjoyment during the customization process only for one product, but not for another. Whether the role of product involvement in the relationship studied in this article is universal or limited to the specific product category should be assessed in future research.

The results of this study are limited by some natural exclusion criteria that may prevented some participants from taking part in the study, i.e. a good knowledge of English, as the questionnaire was not offered in Arabic, and the ownership of an internet capable mobile device. In addition, as some researchers highlight, advertising creativity is certainly important, but not sufficient to win new customers [65]. Amongst others, ads need to be meaningful to the target segment [65], which is a variable that was not measured. Finally, Csikszentmihalyi [66, p. 325, as cited by 67] came to the conclusion that creativity cannot be studied "by isolating individuals and their works from the social and historical milieu in which their actions were carried out". This means that perceived creativity depends on the social context in which it occurs or, in other words, on culture $[67,68]$. For example, the perception and impact of advertising creativity in Korea with its collectivistic, holistic population may be influenced by cultural values such as the collectivistic Confucian norms of the society [69]. The findings of this research should therefore be seen in this light, as the sample consists exclusively of young Saudi consumers.

Thus, future research should assess the impact of perceived advertising creativity in other cultural contexts and with different age groups. Other interesting directions for future research include studying different product or service categories, assessing the impact of perceived advertising creativity on behavioural intention and/or perceived product quality in different forms of advertising, e.g. TV- and video-ads, and exploring the impact of perceived advertising creativity on other dependent variables such as willingness-to-pay or willingness-to-buy. Finally, future studies should examine whether customer's behavioural intentions are not just influenced when they are exposed to a mass customization advertisement, but whether the perceived level of creativity of a product designed by customers themselves and visualized in an online salesconfigurator influences the likelihood to check out, to buy, and/or to pay more for the mass customized product.

\section{ACKNOWLEDGEMENTS}

We acknowledge the financial support of Alfaisal University, IRG project number 18101.

\section{REFERENCES}

[1] Davis, S.M. (1987), Future perfect, New York, USA: AddisonWesley Publishing Company.

[2] Agarwal, N. and Brem, A. (2015), "Strategic business transformation through technology convergence: implications from General Electric's industrial internet initiative", International Journal of Technology Management, Vol. 67, No. 2-4, pp. 196214.

[3] Stojanova, T., Suzic, N. and Orcik, A. (2012), "Implementation of mass customization tools in small and medium enterprises", International Journal of Industrial Engineering and Management, Vol. 3, No. 4, pp. 253-260.

[4] Coletti, P. and Aichner, T. (2011), Mass Customization: An Exploration of European Characteristics. Heidelberg, Germany: Springer.

[5] Modig, E. and Rosengren, S. (2014), "Can advertising creativity affect product perceptions and retailer evaluations?", Journal of Product \& Brand Management, Vol. 23, No. 6, pp. 452-461.

[6] Luchs, M. and Swan, K.S. (2011), "Perspective: The Emergence of Product Design as a Field of Marketing Inquiry", Journal of Product Innovation Management, Vol. 28, No. 3, pp. 327-345.

[7] Suzić, N., Forza, C., Trentin, A. and Anišić, Z. (2018), "Implementation guidelines for mass customization: Current characteristics and suggestions for improvement", Production Planning \& Control, Vol. 29, No. 10, pp. 856-871.

[8] Blecker, T. and Friedrich, G. (2006), Mass Customization: Challenges and Solutions, New York, USA: Springer.

[9] García, A. and de las Morenas, J. (2012), "Integrated Production Attending to Supply Chain, Materials Handling and Storage Requirements", International Journal of Advanced Logistics, Vol. 1, No. 1, pp. 21-32.

[10] Liao, K., Deng, X. and Marsillac, E. (2013), "Factors that influence Chinese automotive suppliers' mass customization capabilities", International Journal of Production Economics, Vol. 146 , No. 1 , pp. 25-36.

[11] Fogliatto, F.S., da Silveira, G.J.C. and Borenstein, D. (2012), "The mass customization decade: An updated review of the literature", International Journal of Production Economics, Vol. 138, No. 1, pp. 14-25.

[12] Suzić, N., Sandrin, E., Suzić, S., Forza, C., Trentin, A., and Anišić, Z. (2018), "Implementation Guidelines for Mass Customization: A Researcher-Oriented View", International Journal of Industrial Engineering and Management, Vol. 9, No. 4, pp. 229-243.

[13] Forza, C. and Salvador, F. (2008), "Application support to product variety management", International Journal of Production Research, Vol. 46, No. 3, pp. 817-836.

[14] Merle, A., Chandon, J.-L. and Roux, E. (2008), “Understanding the perceived value of mass customization: the distinction between product value and experiential value of co-design", Recherche et Applications en Marketing (English Edition), Vol. 23, No. 3, 27-50.

[15] Merle, A., Chandon, J.-L., Roux, E. and Alizon, F. (2010), "Perceived value of the mass-customized product and mass customization experience for individual consumers", Production and Operations Management, Vol. 19, No. 5, pp. 503-514.

[16] Chatzopoulos, C.G. and Weber, M. (2018), "Challenges of Total Customer Experience (TCX): Measurement beyond Touchpoints", International Journal of Industrial Engineering and Management, Vol. 9, No. 4, pp. 187-196.

[17] Trentin, A., Perin, E. and Forza, C. (2014), "Increasing the consumer-perceived benefits of a mass-customization experience through sales-configurator capabilities", Computers in Industry, Vol. 65, No. 4, pp. 693-705.

[18] Franke, N., Schreier, M. and Kaiser, U. (2010), "The "I designed it myself" effect in mass customization", Management Science, Vol. 56, No. 1, pp. 125-140.

[19] Schreier, M. (2006) "The value increment of mass-customized products: an empirical assessment", Journal of Consumer Behaviour, Vol. 5, No. 4, pp. 317-327. 
[20] Sandrin, E. (2017), "Synergic effects of sales-configurator capabilities on consumer-perceived benefits of mass-customized products", International Journal of Industrial Engineering and Management, Vol. 8, No. 3, pp. 177-188.

[21] Sandrin, E., Trentin, A., Grosso, C., and Forza, C. (2017), "Enhancing the consumer-perceived benefits of a masscustomized product through its online sales configurator: An empirical examination", Industrial Management \& Data Systems Vol. 117, No.6, pp. 1295-1315.

[22] Sternberg, R.J. (2012), "The Assessment of Creativity: An Investment-Based Approach", Creativity Research Journal, Vol. 24, No. 1, pp. 3-12.

[23] Amabile, T.M. (1982), "Social psychology of creativity: A consensual assessment technique", Journal of Social Psychology, Vol. 43, pp. 997-1013.

[24] Sullivan, D.M. and Ford, C.M. (2010), "The Alignment of Measures and Constructs in Organizational Research: The Case of Testing Measurement Models of Creativity", Journal of Business and Psychology, Vol. 25, No. 3, pp. 505-521.

[25] Dayan, M. and Di Benedetto, C.A. (2011), "Team intuition as a continuum construct and new product creativity: The role of environmental turbulence, team experience, and stress", Research Policy, Vol. 40, No. 2, pp. 276-286.

[26] Smith, R.E., Chen, J. and Yang, X. (2008), "The Impact of Advertising Creativity on the Hierarchy of Effects", Journal of Advertising, Vol. 37, No. 4, pp. 47-62.

[27] Pich, D.F., Sweeney, J. and Clay, J.A. (1991), "Creative Advertising and the Von Restorff Effect", Psychological Reports, Vol. 69, No. 3, pp. 923-926.

[28] Reinartz, W. and Saffert, P. (2013), "Creativity in Advertising: When It Works and When It Doesn't", Harvard Business Review, Vol. 91, No. 6, pp. 106-111.

[29] Lehnert, K., Till, B.D. and Ospina, J.M. (2014), "Advertising Creativity: The Role of Divergence Versus Meaningfulness", Journal of Advertising, Vol. 43, No. 3, pp. 274-285.

[30] Dahlén, M., Rosengren, S. and Törn, F. (2008), "Advertising Creativity Matters", Journal of Advertising Research, Vol. 48, No. 3, pp. 392-403.

[31] Belch, M.A. and Belch, G.E. (2013), "The Future of Creativity in Advertising", Journal of Promotion Management, Vol. 19, No. 4, pp. 395-399.

[32] Aichner, T., Perkmann, U. and Coletti, P. (2015), "Warum sich Kunden an Mass Customization beteiligen", transfer Werbeforschung \& Praxis, Vol. 61, No. 3, pp. 36-44.

[33] Fiore, A.M., Lee, S.-E., Kunz, G. and Campbell, J.R. (2001), "Relationships between optimum stimulation level and willingness to use mass customization options", Journal of Fashion Marketing and Management, Vol. 5, No. 2, pp. 99-107.

[34] Fiore, A.M., Lee, S.-E. and Kunz, G. (2004), "Individual differences, motivations, and willingness to use a mass customization option for fashion products", European Journal of Marketing, Vol. 38, No. 7, pp. 835-849.

[35] Ryu, K. and Jang, S.S. (2007), "The Effect of Environmental Perceptions on Behavioral Intentions through Emotions: The Case of Upscale Restaurants", Journal of Hospitality \& Tourism Research, Vol. 31, No. 1, pp. 56-72.

[36] Hansen, T., Jensen, J.M. and Solgaard, H.S. (2004), "Predicting online grocery buying intention: a comparison of the theory of reasoned action and the theory of planned behavior", International Journal of Information Management, Vol. 24, No. 6 pp. 539-550.

[37] Warshaw, P.R. and Davis, F.D. (1985), "Disentangling behavioral intention and behavioral expectation", Journal of Experimental Social Psychology, Vol. 21, No. 3, pp. 213-228, 1985

[38] Chu, S.-C. and Kim, Y. (2011), "Determinants of consumer engagement in electronic word-of-mouth (eWOM) in social networking sites", International Journal of Advertising, Vol. 30 No. 1, pp. 47-75.

[39] Lee, H.-H. and Chang, E. (2011), "Consumer Attitudes Toward Online Mass Customization: An Application of Extended Technology Acceptance Model", Journal of Computer-Mediated Communication, Vol. 16, No. 2, pp. 171-199.

[40] Aichner, T. and Gruber, B. (2017), "Managing Customer Touchpoints and Customer Satisfaction in B2B Mass Customization: A Case Study", International Journal of Industria Engineering and Management, Vol. 8, No. 3, pp. 131-140.
[41] Ajzen, I. (1991), "The theory of planned behavior", Organizational Behavior and Human Decision Processes, Vol. 50, No. 2, pp. $179-211$.

[42] Kover, A.J., Goldenberg, S.M. and James, W.L. (1995), "Creativity Vs. Effectiveness? An Integrating Classification for Advertising", Journal of Advertising Research, Vol. 35, No. 6, pp. 29-38.

[43] Ang, S.H. and Low, S.Y.M. (2000), "Exploring the dimensions of ad creativity", Psychology \& Marketing, Vol. 17, No. 10, pp. 835854

[44] Till, B.D. and Baack, D.W. (2005), "Recall and Persuasion: Does Creativity Matter?”, Journal of Advertising, Vol. 34, No. 3, pp. 47-57.

[45] Smith, R.E., MacKenzie, S.B., Yang, X., Buchholz, L. and Darley, W.K. (2007), "Modeling the Determinants and Effects of Creativity in Advertising", Marketing Science, Vol. 26, No. 6, pp. 819-833.

[46] Piller, F.T., Moeslein, K. and Stotko, C.M. (2004), "Does mass customization pay? An economic approach to evaluate customer integration", Production Planning \& Control, Vol. 15, No. 4, pp. 435-444.

[47] Chen, Z. and Dubinsky, A.J. (2003), "A conceptual model of perceived customer value in e-commerce: A preliminary investigation", Psychology \& Marketing, Vol. 20, No. 4, pp. 323347.

[48] Anselmsson, J., Johansson, U. and Persson, N. (2007), "Understanding price premium for grocery products: a conceptual model of customer-based brand equity", Journal of Product \& Brand Management, Vol. 16, No. 6, pp. 401-414

[49] Dahlén, M., Rosengren, S. and Karsberg, J. (2018), "The Effects of Signaling Monetary and Creative Effort in Ads", Journal of Advertising Research, Vol. 58, No. 4, pp. 433-442.

[50] Aichner, T. and Shaltoni, A.M. (2019), "Making market research work in Saudi Arabia", International Journal of Market Research, Vol. 61, No. 1, pp. 10-11.

[51] Aichner, T. and Coletti, P. (2013), "Customers' online shopping preferences in mass customization", Journal of Direct, Data and Digital Marketing Practice, Vol. 15, No. 1, pp. 20-35.

[52] Sandrin, E., Forza, C., Anisic, Z., Suzic, N., Grosso, C., Aichner, T. and Trentin, A. (2017), "Shoe configurators: A comparative analysis of capabilities and benefits", Modrak, V. (Ed.), Mass Customized Manufacturing: Theoretical Concepts and Practical Approaches, Boca Raton, USA: CRC Press, pp. 195-218.

[53] Thang, D.C.L. and Tan, B.L.B. (2003), "Linking consumer perception to preference of retail stores: an empirical assessment of the multi-attributes of store image", Journal of Retailing and Consumer Services, Vol. 10, No. 4, pp. 193-200.

[54] Moutinho, L. (1987), "Consumer Behaviour in Tourism", European Journal of Marketing, Vol. 21, No. 10, pp. 5-44.

[55] Donthu, N., Cherian, J. and Bhargava, M. (1993), "Factors influencing recall of outdoor advertising", Journal of Advertising Research, Vol. 33, No. 3, pp 64-72.

[56] O'Quin, K. and Besemer, S.P. (1989), “The development, reliability, and validity of the revised creative product semantic scale", Creativity Research Journal, Vol. 2, No. 4, pp. 267-278.

[57] White, A. and Smith, B.L. (2001), "Assessing Advertising Creativity Using the Creative Product Semantic Scale", Journal of Advertising Research, Vol. 41, No. 6, pp. 27-34.

[58] Nguyen, N.T. and Biderman, M.D. (2008), "Studying Ethical Judgments and Behavioral Intentions Using Structural Equations: Evidence from the Multidimensional Ethics Scale", Journal of Business Ethics, Vol. 83, No. 4, pp. 627-640.

[59] Dodds, W.B., Monroe, K.B. and Grewal, D. (1991), "Effects of Price, Brand, and Store Information on Buyers' Product Evaluations", Journal of Marketing Research, Vol. 28, No. 3, pp. 307-319.

[60] Podsakoff, P.M., MacKenzie, S.B. and Podsakoff, N.P. (2003), "Common method biases in behavioral research: a critical review of the literature and recommended remedies", Journal of Applied Psychology, Vol. 88, No. 5, pp. 879-903.

[61] Podsakoff, P.M., MacKenzie, S.B. and Podsakoff, N.P. (2012), "Sources of method bias in social science research and recommendations on how to control it", Annual Review of Psychology, Vol. 63, No. 1, pp. 539-569.

[62] Broekhuizen, T.L.J. and Alsem, K.J. (2002), "Success Factors for Mass Customization: A Conceptual Model", Journal of Market-Focused Management, Vol. 5, No. 3, pp. 309-330. 
[63] Aichner, T. (2012), "The Zero Moment of Truth in Mass Customization", International Journal of Industrial Engineering and Management, Vol. 3, No. 4, pp. 173-178.

[64] Schnurr, B. and Scholl-Griessemann, U. (2015), "Beauty or function? How different mass customization toolkits affect customers' process enjoyment', Journal of Consumer Behaviour, Vol. 14, No. 5, pp. 335-343.

[65] Ang, S.H., Leong, S.M., Lee, Y.H., and Lou, S.L. (2014) "Necessary but not sufficient: Beyond novelty in advertising creativity", Journal of Marketing Communications, Vol. 20, No. 3, pp. 214-230.

[66] Csikszentmihalyi, M. (1988), "Society, culture, person: A systems view of creativity", Sternberg, R.J. (Ed.), The nature of creativity. New York, USA: Cambridge University Press, pp. 325-339.

[67] Vanden Bergh, B. and Stuhlfaut, M. (2006), "Is Advertising Creativity Primarily an Individual or a Social Process?", Mass Communication and Society, Vol. 9, No. 4, pp. 373-397.

[68] Twitchell, J.B. (1996), Adcult USA: The triumph of advertising in American culture, New York, USA: Columbia University Press.

[69] Kim, B.H., Han, S. and Yoon, S. (2010), "Advertising Creativity in Korea”, Journal of Advertising, Vol. 39, No. 2, pp. 93-108. 